\section{Perceptions of small animal practitioners and pet owners on professional competencies in veterinary practice: an essential component for curricula design}

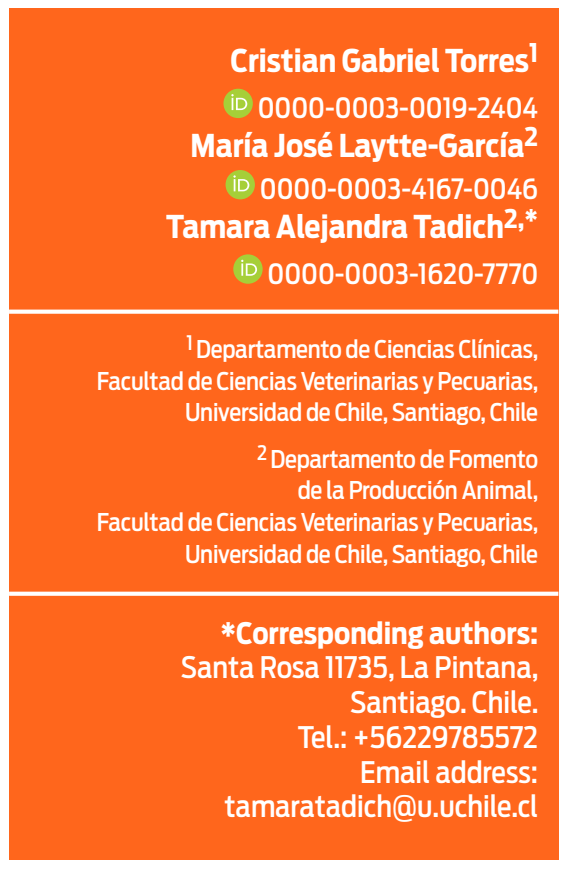

Accepted: $2019-10-01$ Published: $\quad$ 2019-12-11

@) Copyright 2019 Cristian Gabriel Torres et al. open access $\boldsymbol{2}$

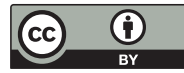

Distributed under Creative Commons CC-BY 4.0

\begin{abstract}
Veterinary schools are responsible for defining their curricula in accordance with societal needs. For this input, listening to stakeholders from outside academia is essential. The aim of this study was to investigate the perception of Chilean small animal practitioners and pet owners on the attributes they consider that constitute a good veterinarian, and to relate these attributes to demographic characteristics. For this, a cross-sectional survey study was designed. A group of 308 small animal practitioners and 328 pet owners from Santiago Metropolitan Region, in Chile, were surveyed. The survey included twenty attributes and questions on demographic characteristics and was applied via email to professionals, and to pet owners sitting in waiting rooms of small animal practices. The majority of respondents in both groups were young adult females. Significant differences in the importance given to 12 out of 20 attributes were found between groups. When asked to prioritize three attributes, both groups mentioned "knowledge about veterinary medicine and surgery", followed by "recognizes own limitations and knows when to seek advice" as well as "good communication skills" in the case of veterinarians. In the case of pet owners, "confidence", "recognizes own limitations" and "knows when to seek advice" were the following attributes. Results showed significant differences within groups according to gender and age, with females and elder respondents giving higher importance to the attributes included in the study. Professional skills should be considered when developing new curricula in Chile, especially those important for local stakeholders.
\end{abstract}

Keywords: Professional skills, Veterinary curricula, Soft competencies, Small animal practitioners, Education.

\section{Cite this as:}

Torres CG, Laytte-García MJ, Tadich-Gallo TA. Perceptions of small animal practitioners and pet owners on professional competencies in veterinary practice: an essential component for curricula design. Veterinaria México OA. 2019;6(4). doi: 10.22201/ fmvz.24486760e.2019.4.683. 


\section{Introduction}

Veterinary schools are responsible for defining their curricula in accordance with societal needs, and in this way ensure that they are forming quality human capital. Professional skills have been defined as "those veterinary competencies that are not discipline specific technical knowledge or technical psychomotor skills". ${ }^{\prime}$ These professional skills are also known as "nontechnical competencies", a term that can be misleading since it implies primacy of the technical skills. ${ }^{1}$ They include personality traits, abilities, core values, motivations and interests that can determine a veterinarian"s success. ${ }^{2}$ Many countries and organizations have set their year one professional skills and competencies for a veterinarian. This is the case of the Royal College of Veterinary Surgeons (RCVS) with the development of essential competencies required for the new veterinary graduate; ${ }^{3}$ the World Organization for Animal Health (OIE), which has defined recommendations on "day one" competencies to ensure the quality of veterinary services, ${ }^{4}$ and the Association of American Veterinary Medical Colleges, which has also set recommendations on non-technical skills. ${ }^{5}$ In Latin America, the Pan American Association of Veterinary Sciences, together with the Pan American Federation of Veterinary Faculties and Schools, have developed recommendations on the profile of the veterinary graduate for 2030, ${ }^{6}$ including mainly technical skills. In Chile, neither technical nor non-technical skills have been defined.

The term "professional skills" has received increasing attention and inclusion in veterinary curricula, without necessarily defining, in the first place, what is understood as veterinary professionalism. ${ }^{7}$ Physicians, on the contrary, have provided multiple definitions, including "the values and behaviors required of physicians".7 In the same line, professional skills such as leadership and communication, are frequently mentioned in veterinary programs, but are not directly assessed during the formation process.

The perception of how important professional skills are defining the success of a veterinarian, or what constitutes a "good veterinarian" has been previously studied. These researches include gender differences among veterinary students; ${ }^{8}$ differences between clients and veterinarians about what attributes constitute a "good vet"; 9 as well as the employer"s perceptions, ${ }^{10}$ among others. For example, Mellanby et al. ${ }^{9}$ found significant differences between attributes considered very important by small animal practitioners, such as "good communication skills", and clients who considered more important "confidence", "knowledge about veterinary medicine and surgery", "cleanliness", "good at explaining technical terms", "patience", "clear about cost of treatment", "ability to work in a team", "honesty", "politeness", "decisiveness", "good with animals" and "good practical skills". To date, there are no studies in Latin American countries regarding the professional skills that veterinarians and pet owners consider important. In Chile, there are 29 veterinary schools, with many of them being under a curriculum update process, moving from a traditional teaching system towards a competency-based approach, where professional skills and competencies need to be included. The development of new curricula can derive from consensus achieved in workshops, focus groups, or open consultation. ${ }^{1}$ This is why the aim of this study was to investigate the perception of Chilean small animal practitioners and pet owners on which attributes constitute a good veterinarian, and how they relate to demographic characteristics. 
Table 1. Description of the classification applied for the demographic characteristics studied

\section{Demographic characteristic}

Address of personal residency or small animal practice location

Age

Gender

Pet owners' level of education

Veterinarians' post graduate studies

University of origin

\section{Description of the measure}

The Metropolitan region was divided in 5 sectors: west, east, south, north and central area. The south and west areas allocate many of the poorest communities, the center is where the historic part of the city is, and the public system offices are concentrated, while in the east and north parts the wealthiest communities are located, as well as the highest concentration of the veterinary practices included in this study

Age was classified in young adult (20-39 years), adult (40-59 years); and elder ( $\geq 60$ years)

Female or male

Education was classified as middle school, high school, technical studies, professional studies

These were classified as with or without any further postgraduate or other type of continuing education program (workshops, diplomas, master degree (MSc), or Doctor degree (PhD)

Traditional or private universities

\section{Material and methods}

\section{Questionnaire}

An electronic and paper-based questionnaire was constructed based on the list of 20 graduate attributes applied by Mellanby et al. ${ }^{9}$ The questionnaire was structured in five parts. The first part was an informed consent, which had to be approved in order to continue with the following sections. The second part consisted in questions regarding demographic characteristics of the person. For pet owners, these included questions regarding gender, age, education level, residence address, and frequency with which they visit the veterinary practice. For veterinarians, questions were related to gender, age, university in which they obtained their degree, postgraduate studies, and the address of the veterinary clinic in which they work. This section is the only one where the questionnaire differed for owners and veterinarians. The descriptions of the measurements used for each demographic characteristic are described in table 1 .

The third part consisted in the question: "In your opinion, how important are the following attributes in a veterinary surgeon?" followed by a list of 20 attributes. Pet owners and veterinarians were asked to rate how important each attribute was for them, in a five point Likert-type scale, which was then converted into a numerical scale: $1=$ not at all important, $2=$ not important, $3=$ indifferent, $4=$ important, and 5 = very important. The fourth part included the question "In your opinion, which of the above are the three most important attributes?". The final part included an open answer question, in case respondents wanted to add an attribute or comment on their own views.

\section{Participants}

Between May and June of 2016, an electronic questionnaire (Google Drive Forms ${ }^{\circledR}$ ) was sent by email to 733 small animal practitioners (SAP) located in Santiago Metropolitan Region, Chile. The list of emails was obtained through the Chilean Association of Veterinarians (COLMEVET) and included all SAP registered for the area. Santiago Metropolitan Region is formed by 52 communities, concentrating $40 \%$ of the Chilean population. ${ }^{11}$ During the same period and region, the 
questionnaire was directly applied to 600 pet owners at waiting rooms of veterinary practices. All participants had to approve an informed consent in order to be included in the study.

\section{Statistical analysis}

First descriptive statistics were applied in order to define the group of pet owners and SAP according to their demographic characteristics. Shapiro-Wilk test was first applied in order to test normality of data. Data did not result to be normally distributed $(p<0.05)$, therefore, nonparametric tests were applied. To compare the level of importance given to each attribute between groups (small animal practitioners and pet owners) the Wilcoxon Rank Sum test was used. To compare within groups according to the demographic characteristic studied (gender, age and education level), Wilcoxon Rank Sum test, or Kruskal-Wallis was performed. As in Mellanby et al. ${ }^{9}$ the association between the responses "very important" compared with the other four categories "not important at all", "not important", "indifferent", and "important" for the three attributes considered as most important by pet owners and SAP, was assessed by the Fisher"s exact test. A significance level of $p<0.05$ was set for all tests applied. All statistical analyses were carried out in Minitab $14{ }^{\circledR}$ (Minitab Inc., State College, PA, USA).

\section{Results and discussion}

Professional skills (nontechnical competencies) have been reported to be essential for the career success of veterinarians, within which satisfaction of clients and other stakeholders comprise an important factor. ${ }^{2}$ Veterinary schools have a responsibility selecting and developing those professional skills. ${ }^{2}$ These professional skills could differ between countries due to demographic differences. Therefore, the aim of this study was to investigate the perception of small animal practitioners and pet owners of which attributes constitute a good vet in Chile.

A total of 314 SAP completed the questionnaire, corresponding to a response rate of $42.83 \%$. From these, 308 had complete information and therefore were included in the analysis. The response rate of pet owners was 55.8\% (335 questionnaires received), of which seven had to be eliminated because they lacked part of the information, resulting in 328 questionnaires included in the final analysis.

In general, from the 308 SAP responses included in the analysis, $62.46 \%$ correspond to women and 37.54\% to men. According to age, $80 \%$ of respondents were young adults (20-39 years), 19\% adults (40-59 years) and only 1\% elder ( $\geq 60$ years) veterinarians. There were 9 universities included in the study, four of which were public universities funded by the state, and 5 were universities financed by private investors. Most respondents were from the public universities (31.8\%). As for the location of their veterinary practice within the studied region, most of them (39\%) are concentrated in the east sector followed by the south (29\%); west (12\%) and, finally, the north and center with 10\% each.

In the case of pet owners, 328 responses were included, of which $67 \%$ belong to women and $33 \%$ to men. Regarding the age of pet owners, $63 \%$ were young adults, 33\% adults and 4\% elders. According to their residence address, most 
of the pet owners included live in the east sector (45\%); followed by the south (23\%); north and west with 12\% each, and finally, the central area with $8 \%$. As for the pet owners" level of education 52\% have a professional career, 20\% are still in university and $15 \%$ have technical studies. A lower percentage of owners had high school studies (10\%) or only completed middle school (2\%). Pet owners also answered how often they take their pets to the vet. Most owners take their pet once or more times a year (65\%); 31\% only when their pet is sick, and 4\% declare to take them, in average, once every two years.

One of the main findings of this study was that, as in Mellanby et al. ${ }^{9}$, differences were found in the level of importance given to 12 of the 20 attributes studied, amongst SAP and pet owners (Fig. 1). Of these 12 attributes, 9 were the same as in Mellanby et al. ${ }^{9}$ except for "decisiveness", "confidence", and "honesty", for which no differences were found in the present study. Significant differences were found for "professional appearance" ( $p<0.001)$, "politeness" ( $p=0.006)$, "recognizes own limitations and knows when to seek advice" ( $p<0.001$ ), as well as "good communication skills" ( $p=0.048)$ (Fig. 1), which were considered as "very important" attributes by SAP. On the other hand, "compassion for patients" $(p=0.002)$, "compassion for owners" ( $p<0.001)$, "good practical skills" ( $p<0.001)$, "good with animals" ( $p<0.001)$ and "clear about treatment costs" ( $p=0.003)$ were considered more important by pet owners. Pet owners in this study gave certain attributes a similar degree of importance as those consulted in Mellanby et al. ${ }^{9}$, which indicates that stakeholders located in different countries have similar expectations in what they consider to be a "good vet". This provides further evidence to support that these attributes should be considered when developing new curricula, since Universities are responsible of ensuring that veterinary training meets social needs. ${ }^{12}$ On the other hand, attributes such as "compassion for patients" and "compassion for owners" could be related to the empathy levels showed by practitioners. In the case of Chile, it has been reported that veterinary students have a significant decrease in their level of empathy towards animals, and a small decrease in their empathy towards humans as they reach the final years of their career. ${ }^{13}$ The authors explain this decrease as a result of a lack of emphasis on the importance of the human-animal bond, and insufficient courses on animal welfare and ethics. ${ }^{13}$

It is important to notice that pet owners and SAP agreed in 8 attributes, similar to Schull et al. ${ }^{10}$, where a close agreement in the importance provided to professional skills was reported between new graduates and employers. For example, "honesty" and "ability to listen" were regarded as very important for both groups in the present study, and were also mentioned in the top ten "soft skills" by Schull et al. ${ }^{10}$

When asked to prioritize three attributes, "knowledge about veterinary medicine and surgery" was the top one response for both groups (75\% of pet owners and $85 \%$ of veterinarians; Fig. 2). Interestingly, this was also the number one attribute reported by clients in Mellanby et al. ${ }^{9}$, but not by veterinarians, who reported "good communication skills" as the number one attribute of a good veterinarian. "Good communication skills" was reported within their top three by only $29 \%$ of SAP and by none of the pet owners in the present study. This result is contrary to other studies, where it has been reported that clients place more importance on a veterinarian's communication skills than on technical skills. ${ }^{14}$ Communication skills have been reported as one of the most important skills in various studies. 1, 10,15 The fact that it was not mentioned within the prioritization by pet owners could 


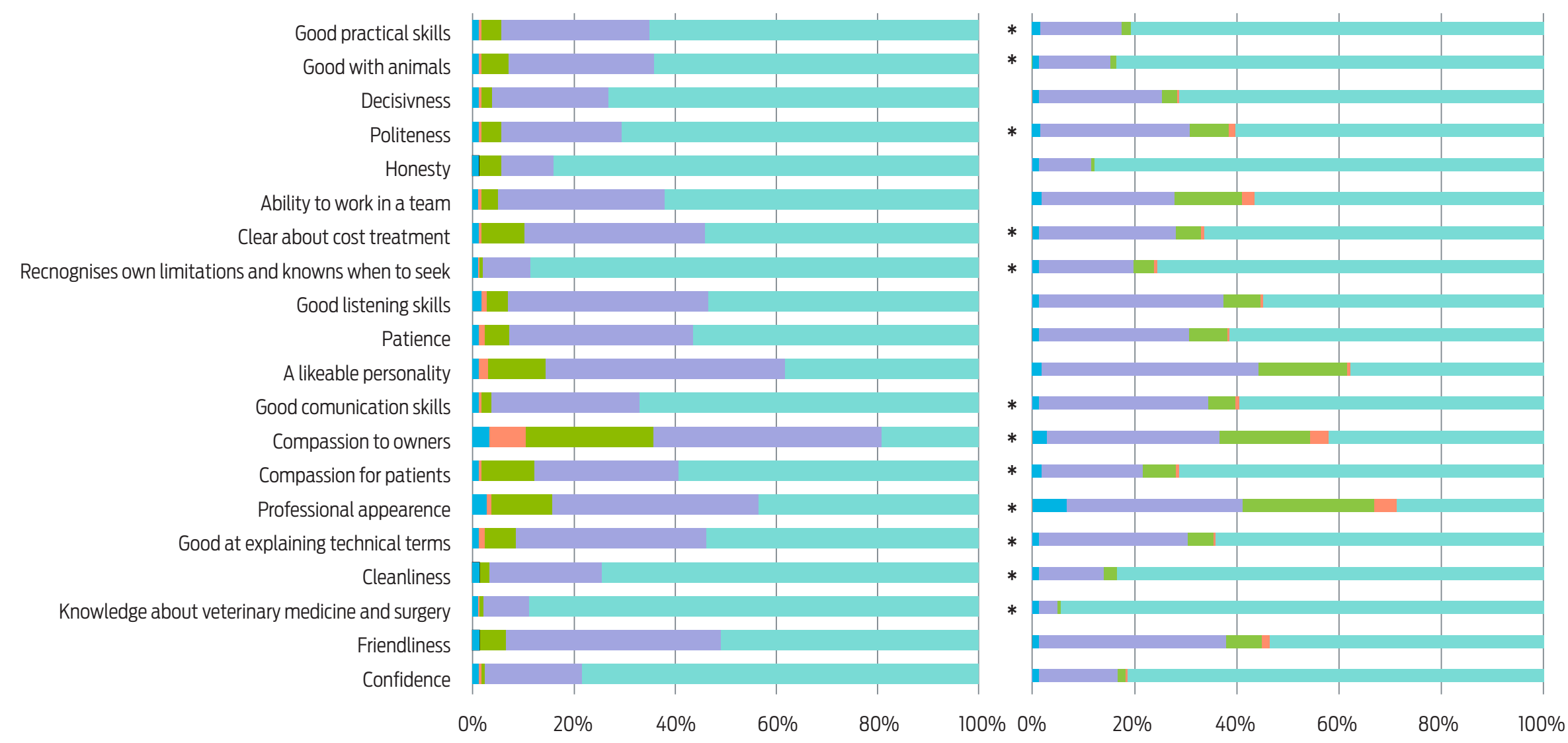

Not at all important $\quad$ Not important Indifferent Important $\quad$ Very important

Figure 1. Level of importance given by small animal practitioners (SAP) and pet owners to each of the twenty attributes to be a "good vet". All bar charts are sorted by the percentage of respondents that considered a specific attribute as "very important".

*Significant differences $(p<0.05)$ between small animal practitioners and pet owners in the importance provided to each attribute according to the Wilcoxon rank sum test. 


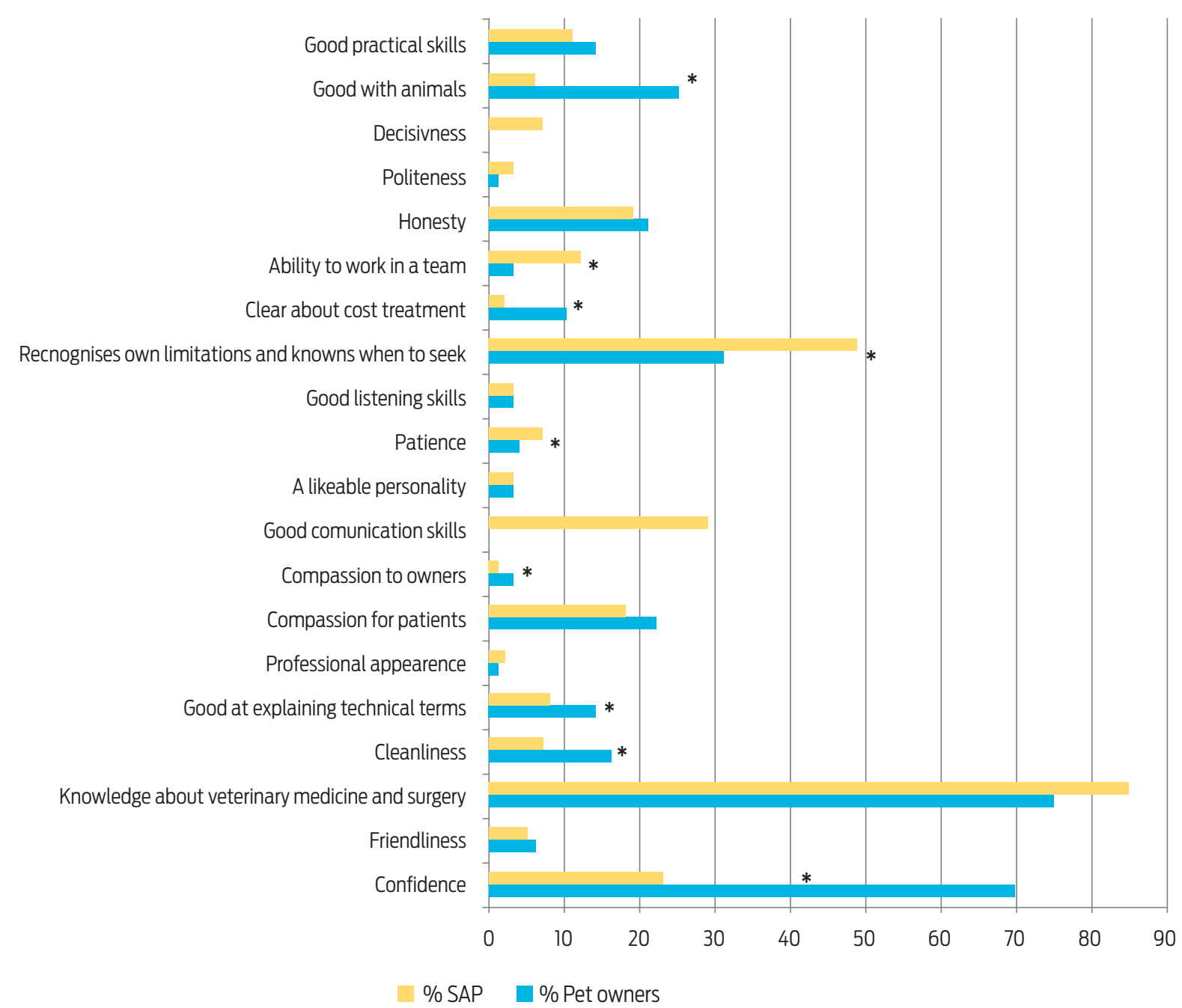

Figure 2. Percentage of small animal practitioners (SAP) and pet owners that considered an attribute to be among their top three attributes.

"Significant differences $(\mathrm{p}<0.05)$, according to the Fishers exact test, in the proportion of SAP, and pet owners who considered an attribute in their "top three" attributes. 
be due to the similarity or closeness to other attributes included in the list, such as "good at explaining technical terms", or "clear about cost of treatment", which involve communication.

In the case of pet owners, the second priority was given to "confidence" (40\%) and thirdly to "recognizes own limitations and knows when to seek advice" (31\%). Significant differences between the proportion of responses listed as their top three among pet owners and SAP were found for: "knowledge about veterinary medicine and surgery" ( $p=0.001)$; "recognizes own limitations and knows when to seek advice" ( $p<0.001)$, "ability to work in a team" ( $p<0.001)$, with a larger percentage of SAP considering them more important; and "good with animals" $(p<0.001)$, "clear about cost of treatment" ( $p<0.001)$, "compassion for owners" $(p=0.042)$, "good at explaining technical terms" ( $p=0.019)$, "cleanliness" ( $p<0.001)$, and "confidence" ( $p<0.001)$ being more important for pet owners (Fig. 2).

Regarding geographical location within the Santiago Metropolitan Region, significant differences were found only for "compassion for owners" $(p=0.028)$ according to the SAP. This attribute was considered less important for those located in the west area. For pet owners, differences in relation to their residence address were found for "confidence" ( $p=0.029)$, with those in the east area scoring higher; and for those living in the west area "good with animals" was of a higher importance $(p=0.002)$. Only one attribute presented significant differences amongst areas by SAP, this was "compassion for owners" in the west sector, where it scored the lowest level of importance. This is the same sector in which the attribute "good with animals" was considered significantly more important by the owners, of which the majority only had middle school or high school studies. On the other hand, owners that reside in the east sector considered "confidence" as more important, this is a high-income sector and owners might be expecting practitioners to be more self-confident. It is worth noting that in this sector, pet owners had the highest education level.

All respondents were over 18 years old, and were divided into young adults, adults and elder respondents. In the case of SAP, age was not a differentiating factor in the importance given to the studied attributes, although elder veterinarians tended to score higher, in average, in most attributes, with the exception of "professional appearance", "compassion for patients", "compassion for owners", "good communication skills", "likeable personality", and "good with animals". On the other hand, for pet owners, age was a significant factor $(p<0.05)$ for 10 out of the 20 attributes. Elder pet owners scored as significantly more important "friendliness" $(p=0.007)$, "professional appearance" ( $p<0.001)$, "compassion for patients" $(p=0.018)$, "compassion for owners" ( $p=0.001)$, "good communication skills" ( $p=0.012)$, a "likeable personality" ( $p=0.013)$, "good listening skills" $(p=0.004)$, "recognizes own limitations and knows when to seek advice" $(p=0.041)$, "ability to work in a team" ( $p=0.032)$ and "politeness" ( $p=0.004)$ (Tables 2 and 3$)$. Elder respondents scored with greater importance most of the attributes. For SAP, these differences were not significant between age groups, but in the case of pet owners they were for $50 \%$ of the attributes. Clarke et al. ${ }^{16}$ also reported that in Australia, clients over 49 years old were more likely to appreciate veterinary technologists (paravets that support clinical and laboratory work of veterinarians) being more flexible, cheerful and agreeable. Elder respondents scoring higher for most attributes could be related to the fact that some competencies are acquired in later career stages as a result of experience ${ }^{1}$, with younger people not necessarily considering them important. 
Table 2. Median scores and ranges of responses provided by small animal practitioners according to demographic characteristics.

\begin{tabular}{|c|c|c|c|c|c|c|c|c|c|c|c|c|c|}
\hline & \multicolumn{4}{|c|}{ Age } & \multicolumn{3}{|c|}{ Gender } & \multicolumn{6}{|c|}{ Education } \\
\hline & $\begin{array}{c}\text { Young } \\
\text { adult } \\
\text { Median } \\
\text { [range] }\end{array}$ & $\begin{array}{l}\text { Adult } \\
\text { Median } \\
\text { [range] }\end{array}$ & $\begin{array}{l}\text { Elder } \\
\text { Median } \\
\text { [range] }\end{array}$ & p-value & $\begin{array}{l}\text { Female } \\
\text { Median } \\
\text { [range] }\end{array}$ & $\begin{array}{l}\text { Male } \\
\text { Median } \\
\text { [range] }\end{array}$ & p-value & $\begin{array}{l}\text { Middle } \\
\text { School } \\
\text { Median } \\
\text { [range] }\end{array}$ & $\begin{array}{c}\text { High } \\
\text { School } \\
\text { Median } \\
\text { [range] }\end{array}$ & p-value & $\begin{array}{l}\text { Technical } \\
\text { Studies } \\
\text { Median } \\
\text { [range] }\end{array}$ & \begin{tabular}{|c|} 
Professional \\
studies \\
Median
\end{tabular} & p-value \\
\hline Confidence & $5[1-5]$ & $5[4-5]$ & $5[5-5]$ & 0.138 & $5[1-5]$ & $5[1-5]$ & 0.531 & $5[1-5]$ & $5[1-5]$ & 0.715 & $5[1-5]$ & $5[1-5]$ & 0.746 \\
\hline Friendliness & $4[1-5]$ & $5[3-5]$ & $4.5[4-5]$ & 0.144 & $5[1-5]$ & $5[1-5]$ & 0.991 & $5[1-5]$ & $4[1-5]$ & 0.381 & $5[1-5]$ & $5[1-5]$ & 0.952 \\
\hline $\begin{array}{l}\text { Knowledge about veterinary medicine } \\
\text { and surgery }\end{array}$ & $5[1-5]$ & $5[3-5]$ & $5[5-5]$ & 0.76 & $5[1-5]$ & $5[1-5]$ & 0.888 & $5[1-5]$ & $5[1-5]$ & 0.87 & $5[1-5]$ & $5[4-5]$ & 0.415 \\
\hline Cleanliness & $5[1-5]$ & $5[4-5]$ & $5[4-5]$ & 0.245 & $5[1-5]$ & $5[1-5]$ & 0.551 & $5[1-5]$ & $5[1-5]$ & 0.769 & $5[1-5]$ & $5[1-5]$ & 0.348 \\
\hline Good at explaining technical terms & $5[1-5]$ & $5[2-5]$ & $5[4-5]$ & 0.448 & $5[1-5]$ & $4[1-5]$ & 0.049 & $5[1-5]$ & $5[1-5]$ & 0.668 & $5[1-5]$ & $5[1-5]$ & 0.653 \\
\hline Professional appearence & $4[1-5]$ & $4[4-5]$ & $4[3-5]$ & 0.101 & $4[1-5]$ & $5[1-5]$ & 0.038 & $4[1-5]$ & $4[1-5]$ & 0.074 & $4[1-5]$ & $4[1-5]$ & 0.355 \\
\hline Compassion for patients & $5[1-5]$ & $5[3-5]$ & $4[3-4]$ & 0.063 & $5[1-5]$ & $4[1-5]$ & 0.004 & $5[1-5]$ & $5[1-5]$ & 0.883 & $5[1-5]$ & $5[1-5]$ & 0.003 \\
\hline Compassion for owners & $4[1-5]$ & $4[1-5]$ & $3.5[2-4]$ & 0.433 & $4[1-5]$ & 4 [1-5] & 0.097 & $4[1-5]$ & $4[1-5]$ & 0.601 & $4[1-5]$ & $4[1-5]$ & 0.128 \\
\hline Good communication skills & $5[1-5]$ & $5[3-5]$ & $4[4-5]$ & 0.077 & $5[1-5]$ & $5[1-5]$ & 0.861 & $5[1-5]$ & $5[1-5]$ & 0.859 & $5[1-5]$ & $5[1-5]$ & 0.560 \\
\hline A likeable personality & $4[1-5]$ & $4[3-5]$ & $4[4-4]$ & 0.141 & $4[1-5]$ & $4[1-5]$ & 0.528 & $4[1-5]$ & $4[1-5]$ & 0.791 & $4[1-5]$ & $4[1-5]$ & 0.438 \\
\hline Patience & $5[1-5]$ & $5[3-5]$ & $5[4-5]$ & 0.473 & $5[1-5]$ & $5[1-5]$ & 0.407 & $5[1-5]$ & $5[1-5]$ & 0.401 & $5[1-5]$ & $5[1-5]$ & 0.604 \\
\hline Good listening skills & $5[1-5]$ & $5[1-5]$ & $5[4-5]$ & 0.6 & $5[1-5]$ & $5[1-5]$ & 0.554 & $5[1-5]$ & $5[1-5]$ & 0.82 & $5[1-5]$ & $5[1-5]$ & 0.357 \\
\hline $\begin{array}{l}\text { Recognises own limitations and knows } \\
\text { when to seek advice }\end{array}$ & $5[1-5]$ & $5[3-5]$ & $5[4-5]$ & 0.359 & $5[1-5]$ & $5[1-5]$ & 0.135 & $5[1-5]$ & $5[1-5]$ & 0.94 & $5[1-5]$ & $5[1-5]$ & 0.119 \\
\hline Clear about cost treatment & $5[1-5]$ & $5[3-5]$ & $5[4-5]$ & 0.65 & $5[1-5]$ & $5[1-5]$ & 0.327 & $5[1-5]$ & $5[1-5]$ & 0305 & $5[1-5]$ & $5[1-5]$ & 0.26 \\
\hline Ability to work in a team & $5[1-5]$ & $5[3-5]$ & $4.5[4-5]$ & 0.762 & $5[1-5]$ & $5[1-5]$ & 0.728 & $5[1-5]$ & $5[1-5]$ & 0.209 & $5[1-5]$ & $5[1-5]$ & 0.976 \\
\hline Honesty & $5[1-5]$ & $5[4-5]$ & $5[4-5]$ & 0.389 & $5[1-5]$ & $5[1-5]$ & 0.483 & $5[1-5]$ & $5[1-5]$ & 0.844 & $5[1-5]$ & $5[1-5]$ & 0.842 \\
\hline Politeness & $5[1-5]$ & $5[3-5]$ & $5[4-5]$ & 0.772 & $5[1-5]$ & $5[1-5]$ & 0.046 & $5[1-5]$ & $5[1-5]$ & 0.72 .1 & $5[1-5]$ & $5[1-5]$ & 0.135 \\
\hline Decisivness & $5[1-5]$ & $5[3-5]$ & $5[5-5]$ & 0.462 & $5[1-5]$ & $5[1-5]$ & 0.545 & $5[1-5]$ & $5[1-5]$ & 0.755 & $5[1-5]$ & $5[1-5]$ & 0.298 \\
\hline Good with animals & $5[1-5]$ & $5[3-5]$ & $4[4-5]$ & 0.222 & $5[1-5]$ & $5[1-5]$ & 0.001 & $5[1-5]$ & $5[1-5]$ & 0.184 & $5[1-5]$ & $5[1-5]$ & 0.541 \\
\hline Good practical skills & $5[1-5]$ & $5[3-5]$ & $5[5-5]$ & 0.341 & $5[1-5]$ & $5[1-5]$ & 0.755 & $5[1-5]$ & $5[1-5]$ & 0.04 & $5[1-5]$ & $5[1-5]$ & 0.678 \\
\hline
\end{tabular}

Significant differences $(\mathrm{p}<0.05)$ within each demographic characteristic, according to the Wilcoxon rank sum test or Kruskal-Wallis, are marked in bold. Wilcoxon rank sum test and Kruskal-Wallis are applied to test if there are differences between the distribution of the samples. 
Table 3. Median scores and ranges of the responses provided by pet owners, according to demographic characteristics.

\begin{tabular}{|c|c|c|c|c|c|c|c|c|c|c|c|c|c|c|c|c|c|c|c|c|}
\hline \multirow[b]{3}{*}{ Confidence } & \multicolumn{7}{|c|}{ Age } & \multicolumn{5}{|c|}{ Gender } & \multicolumn{8}{|c|}{ Education } \\
\hline & \multirow{2}{*}{\multicolumn{2}{|c|}{$\begin{array}{c}\text { Young } \\
\text { adult } \\
\text { Median } \\
\text { [range] } \\
5[1-5]\end{array}$}} & \multicolumn{2}{|c|}{$\begin{array}{l}\text { Adult } \\
\text { Median } \\
\text { [range] }\end{array}$} & \multicolumn{2}{|c|}{$\begin{array}{l}\text { Elder } \\
\text { Median } \\
\text { [range] }\end{array}$} & \multirow{2}{*}{$\begin{array}{l}\text { p-value } \\
0.623\end{array}$} & \multicolumn{2}{|c|}{$\begin{array}{l}\text { Female } \\
\text { Median } \\
\text { [range] }\end{array}$} & \multicolumn{2}{|c|}{$\begin{array}{l}\text { Male } \\
\text { Median } \\
\text { [range] }\end{array}$} & \multirow{2}{*}{$\begin{array}{l}\text { p-value } \\
<0.001\end{array}$} & \multicolumn{2}{|c|}{$\begin{array}{l}\text { Middle } \\
\text { School } \\
\text { Median } \\
\text { [range] }\end{array}$} & \multicolumn{2}{|c|}{$\begin{array}{l}\text { High } \\
\text { School } \\
\text { Median } \\
\text { [range] }\end{array}$} & \multirow{2}{*}{$\begin{array}{c}\text { Technical } \\
\text { Studies } \\
\text { Median } \\
\text { [range] } \\
5 \text { [1-5] }\end{array}$} & \multicolumn{2}{|c|}{$\begin{array}{l}\text { Professional } \\
\text { studies } \\
\text { Median }\end{array}$} & \multirow{2}{*}{$\begin{array}{l}\text { p-value } \\
0.462\end{array}$} \\
\hline & & & 5 & {$[1-51$} & 5 & [4-5] & & 5 & [1-5] & 5 & [1-5] & & 5 & [4-5] & 5 & {$[4-5]$} & & 5 & [1-5] & \\
\hline Friendliness & \multicolumn{2}{|c|}{$4.5[1-5]$} & 5 & [1-5] & 5 & [4-5] & 0.007 & 5 & [1-5] & 4 & [1-5] & $<0.001$ & 5 & [4-5] & 5 & [3-5] & $5[1-5]$ & 5 & [1-5] & 0.235 \\
\hline $\begin{array}{l}\text { Knowledge about veterinary medicine and } \\
\text { surgery }\end{array}$ & 5 & {$[1-5]$} & 5 & {$[1-5]$} & 5 & [4-5] & 0.763 & 5 & [1-5] & 5 & {$[1-5]$} & 0.12 .1 & 5 & {$[5-5]$} & 5 & [5-5] & $5[1-5]$ & 5 & {$[1-5]$} & 0.394 \\
\hline Cleanliness & 5 & [1-5] & 5 & [1-5] & 5 & [5-5] & 0.191 & 5 & [1-5] & 5 & [1-5] & 0.442 & 5 & [5-5] & 5 & [3-5] & $5[1-5]$ & 5 & [1-5] & 0.401 \\
\hline Good at explaining technical terms & 5 & [1-5] & 5 & [1-5] & 5 & [4-5] & 0.168 & 5 & [1-5] & 5 & [1-5] & 0.047 & 5 & [5-5] & 5 & [3-5] & $5[1-5]$ & 5 & [1-5] & 0.022 \\
\hline Professional appearence & 4 & [1-5] & 4 & [1-5] & 5 & [4-5] & $<0.001$ & 4 & [1-5] & 4 & [1-5] & 0.349 & 4 & [3-5] & 5 & [1-5] & $4[1-5]$ & 4 & [1-5] & $<0.001$ \\
\hline Compassion for patients & 5 & [1-5] & 5 & [1-5] & 5 & [4-5] & 0.018 & 5 & [1-5] & 5 & [1-5] & 0.016 & & [5-5] & 5 & [4-5] & $5[1-5]$ & 5 & [1-5] & 0.032 \\
\hline Compassion for owners & 4 & [1-5] & 4 & [1-5] & 4 & [4-5] & 0.001 & 4 & [1-5] & 4 & [1-5] & $<0.001$ & 5 & [4-5] & 5 & [3-5] & $4[1-5]$ & 4 & [1-5] & 0.039 \\
\hline Good communication skills & 5 & {$[1-5]$} & 5 & [1-5] & 5 & [4-5] & 0.012 & 5 & [1-5] & 5 & {$[1-5]$} & 0.031 & 5 & {$[4-5]$} & 5 & {$[4-5]$} & $5[1-5]$ & 5 & {$[1-5]$} & 0.066 \\
\hline A likeable personality & 4 & {$[1-5]$} & 4 & [1-5] & 5 & [4-5] & 0.013 & 4 & [1-5] & 4 & [1-5] & 0.085 & 5 & [4-5] & 5 & [3-5] & $4[1-5]$ & 4 & [1-5] & $<0.001$ \\
\hline Patience & 5 & {$[1-5]$} & 5 & {$[1-5]$} & 5 & [3-5] & 0.122 & 5 & [1-5] & 4 & [1-5] & 0.001 & 5 & {$[5-5]$} & 5 & [3-5] & $5[1-5]$ & 5 & {$[1-5]$} & $<0.001$ \\
\hline Good listening skills & & [1-5] & 5 & {$[1-5]$} & 5 & [4-5] & 0.004 & 5 & [1-5] & 4 & [1-5] & 0.007 & 5 & [4-5] & 5 & [3-5] & $5[1-5]$ & 4 & [1-5] & 0.014 \\
\hline \multicolumn{21}{|l|}{$\begin{array}{l}\text { Recognises own limitations and knows when to } \\
\text { seek }\end{array}$} \\
\hline \multirow[t]{2}{*}{ Advice } & 5 & {$[1-5]$} & 5 & {$[1-5]$} & 5 & [4-5] & 0.041 & 5 & {$[1-5]$} & 5 & {$[1-5]$} & 0.081 & 5 & {$[4-5]$} & 5 & [3-5] & 5 [1-5] & 5 & {$[1-5]$} & \\
\hline & & & & & & & & & & & & & & & & & & & & 0.533 \\
\hline Clear about cost treatment & 5 & [1-5] & 5 & {$[1-5]$} & 5 & [4-5] & 0.323 & 5 & [1-5] & 5 & [1-5] & 0.521 & 5 & [4-5] & 5 & [3-5] & $5[1-5]$ & 5 & [1-5] & 0.206 \\
\hline Ability to work in a team & 5 & [1-5] & 5 & [1-5] & 5 & [4-5] & 0.032 & 5 & [1-5] & 4 & [1-5] & 0.013 & 5 & [4-5] & 5 & [3-5] & $5[1-5]$ & 5 & [1-5] & 0.026 \\
\hline Honesty & 5 & [1-5] & 5 & {$[4-5]$} & 5 & [4-5] & 0.87 & 5 & [1-5] & 5 & [1-5] & 0.044 & 5 & {$[4-51$} & 5 & [4-5] & $5[1-5]$ & 5 & [1-5] & 0.133 \\
\hline Politeness & 5 & [1-5] & 5 & {$[1-5]$} & 5 & [4-5] & 0.004 & 5 & [1-5] & 5 & [1-5] & 0.135 & 5 & [5-5] & 5 & [3-5] & $5[1-5]$ & 5 & [1-5] & 0.006 \\
\hline Decisivness & 5 & [1-5] & 5 & [1-5] & 5 & [3-5] & 0.172 & 5 & [1-5] & 5 & [1-5] & 0.005 & 5 & {$[5-5]$} & 5 & [4-5] & $5[1-5]$ & 5 & [1-5] & 0.001 \\
\hline Good with animals & 5 & [1-5] & 5 & [3-5] & 5 & [1-5] & 0.271 & 5 & [1-5] & 5 & {$[1-53$} & 0.001 & 5 & [5-5] & 5 & [4-5] & $5[1-5]$ & 5 & [1-5] & 0.055 \\
\hline Good practical skills & 5 & [1-5] & 5 & [1-5] & 5 & [4-5] & 0.245 & 5 & [1-5] & 5 & [1-5] & 0.004 & 5 & [5-5] & 5 & {$[4-5]$} & $5[1-5]$ & 5 & [1-5] & 0.144 \\
\hline
\end{tabular}

Significant differences $(\mathrm{p}<0.05)$ within each demographic characteristic, according to the Wilcoxon rank sum test or Kruskal-Wallis, are marked in bold. 
Most respondents, in both groups, were female, as in Kogan et al. ${ }^{8}$, Schull et al. ${ }^{10}$, Clarke et al. ${ }^{16}$, and Doucet and Vrins. ${ }^{17}$ This can be related to the fact that women are more willing to participate in activities such as surveys that involve communication and sharing information. ${ }^{18,19}$ Gender differences were found among SAP for five of the twenty attributes; "good at explaining technical terms", "professional appearance", and "politeness" were scored higher by men; while "compassion for patients" and "good with animals", were scored higher by women. For pet owners these differences were present for thirteen of the twenty attributes, with women scoring higher (Tables 2 and 3).

Not many studies take gender into account when looking at these "professional skills in veterinarians". ${ }^{20,21}$ Nevertheless, it has been reported that female veterinary students have higher expectations of themselves and feel they need to outperform by holding to stricter standards than men.8,22,23 For example, Kogan et al. ${ }^{8}$ reported that female veterinary students scored significantly higher than men in those characteristics that defined a successful veterinary student. One of the problems that might result from these unrealistic high standards is that women put excessive pressure on themselves, which can result in anxiety or depressive disorders. ${ }^{2}$ In the present study, female pet owners rated with greater importance 13 out of the 20 attributes, showing higher expectations than male pet owners on the attributes that constitute a good veterinarian. These results are similar to those reported by Clarke et al. ${ }^{16}$, where female clients seemed to be more likely to respond to a veterinary technologist who was sociable and empathic. On the contrary, in the case of SAP, female veterinarians only rated with higher importance than their male colleges "compassion for patients" and "good with animals"; while men rated with higher importance "good at explaining technical terms", "professional appearance" and "politeness". Again "compassion for patients" and "good with animals" are attitudes that are related to higher levels of empathy towards animals, levels that were reported to be significantly higher in female veterinary students than in male students in Chile, ${ }^{13}$ as in other countries. ${ }^{24,25}$ The attributes rated as more important by male small animal practitioners are more practical abilities.

For SAP, education was assessed in terms of the type of university where they came from, as well as the existence of postgraduate studies or continuing education. According to the type of university of origin, significant differences were found only for "compassion for patients", with veterinarians from private universities giving it a higher importance. Significant differences were also found for "good practical skills" attribute, that was given a higher importance by those veterinarians that did not count with any further studies. In the case of pet owners, significant differences according to level of studies were found for ten attributes. Owners with professional studies always presented significantly lower mean scores (Tables 2 and 3).

It is important to highlight that the higher the level of education, the lower importance provided to the "professional skills" in both groups. This requires further studies, but it is interesting to point out that the lower the level of education in the case of pet owners, the higher the importance provided to skills such as "good at explaining technical terms", "patience", which were scored as "very important" by all respondents that only completed middle school, while "professional appearance" had the lowest average score. In the case of SAP, almost no differences were found between having or not postgraduate studies, or the university of origin. Only "good practical skills" was scored significantly higher by practitioners without any postgrad- 
Table 4. Absolute frequency of other attributes reported by small animal practitioners and pet owners in the open response section

\begin{tabular}{|c|c|}
\hline \multicolumn{2}{|c|}{ Small animal practitioners } \\
\hline Attribute & Frequency \\
\hline Continuous update of knowledge & 31 \\
\hline Empathy & 28 \\
\hline Companionship with colleagues & 20 \\
\hline Administration abilities & 10 \\
\hline Extension work with community & 9 \\
\hline Ethical behaviour & 8 \\
\hline Problem resolution & 7 \\
\hline Humility & 6 \\
\hline Social commitment & 5 \\
\hline Pet owners & \\
\hline Attribute & Frequency \\
\hline Reasonable prices & 20 \\
\hline Availability & 13 \\
\hline Ethical behaviour & 12 \\
\hline Empathy & 11 \\
\hline Love and respect for animals & 9 \\
\hline Concern for patients & 8 \\
\hline Assertive diagnosis and treatments for pets & 8 \\
\hline
\end{tabular}

uate studies, which could be associated with a more technical view of the career. According to the university of origin "compassion for patients" was the only attribute where differences were found, scoring higher for those that studied in a private type of university. It cannot be ruled out that maybe a higher number of female veterinarians came from these universities, and that this factor might be confounding the results, considering that no other differences were found.

When asked if they wanted to add any other comments or views on the subject, both pet owners and SAP added some attributes or skills that they thought to be important. In the case of SAP, the most frequent concepts were "continues knowledge update", "empathy" and "companionship with colleagues". For pet owners, these were "reasonable prices", "availability", and "ethical behavior" (Table 4).

\section{Conclusions}

Since curriculum reforms are a time-consuming process, they require evidence-based data on which to propose changes. Private practitioners and other stakeholders can better identify the skills and knowledge needed by new graduates since they act as practicing veterinarians and employers, while academicians are usually specialists in defined areas and not necessarily can provide this outside broader view. It is essential, then, to consider the opinion of veterinary practitioners and animal owners when updating curricula at veterinary schools. The importance given to the attributes studied in this survey did not differ from results from other countries. They provide relevant information, from local stakeholders, on the professional skills that should be considered when implementing new curricula. 


\section{References}

1. Cake MA, Bell MA, Williams JC, Brown FJL, Dozier M, Rhind SM, et al. Which professional non-technical competencies are most important to the success of graduate veterinarians? A best evidence medical Education (BEME) systematic review: BEME guide No 38. Med Teach. 2016;38:550-63.

2. Lewis RE, Klausner JS. Nontechnical competencies underlying career success as a veterinarian. J Am Vet Med Assoc. 2003;222:1690-6.

3. Royal College of Veterinary Science (RCVS). RCVS Day one competences. RCVS Setting veterinary standards 2014. Available at: http://www.rcvs.org. uk/document-library/day-one-competences/day-one-competences-updated-26-march-2014.pdf

4. World Organisation For Animal Health (OIE). OIE recommendations on the competencies of graduating veterinarians Day 1 graduates to assure national veterinary services of quality. PVS Pathway, 2012. Available at: http://www.oie. int/fileadmin/Home/eng/Support_to_OIE_Members/Vet_Edu_AHG/DAY_1/ DAYONE-B-ang-vC.pdf

5. Willis NG, Monroe FA, Potworowski JA, Evans BR, Smith JE, Andrews KJ, et al. Envisioning the future of veterinary medical education: the Association of American Veterinary Medical Colleges Foresight Project, Final report. J Vet Med Educ. 2007;34:1-41.

6. Taylor JJ. Perfil profesional del Médico Veterinario en Latinoamérica, visión al 2030. Asociación Panamericana de Ciencias Veterinarias y Federación Panamericana de Facultades y Escuelas de Ciencias Veterinarias, 2013. Available at: http://www.panvet.org/wp-content/uploads/2014/10/Perfil-MV_2013.pdf

7. Mossop LH. Is it time to define veterinary professionalism? J Vet Med Educ. 2012;39:93-100.

8. Kogan LR, Mcconnell SL, Schoenfeld-Tacher R. Gender differences and the definition of success: male and female veterinary students' career and work performance expectations. J Vet Med Educ. 2004;31:154-60.

9. Mellanby RJ, Rhind SM, Bell C, Shaw DJ, Gifford J, Fennell D, et al. Perception of clients and veterinarians on what attributes constitute "a good vet". Vet Rec. 2011;168:616.

10. Schull DN, Morton JM, Coleman GT, Mills PC. Final-year student and employer views of essential personal, interpersonal and professional attributes for new veterinary science graduates. Aust Vet J. 2012;90:100-4.

11. Intendencia Metropolitana. Información geográfica. 2016. Available at: http:// www.intendenciametropolitana.gov.cl/informacion_geografica_2.html

12. Schull DN, Morton JM, Coleman GT, Mills PC. Veterinary students' perception of their day-one abilities before and after final year clinical practice-based training. J Vet Med Educ. 2011; 38:251-61.

13. Calderón-Amor J, Luna-Fernández D, Tadich T. Study of the levels of human-human and human-animal empathy in veterinary medical students from Chile. J Vet Med Educ. 2017;44:179-86.

14. Tinga $C E$, Adams $C L$, Bonnet BN, Ribble CS. Survey of veterinary technical and professional skills in students and recent graduates of a veterinary college. J Am Vet Med Assoc. 2001;219:924-31.

15. Greenfield $C L$, Johnson AL, Schaeffer DJ. Frequency of use of various procedures, skills, and areas of knowledge among veterinarians in private small 
animal exclusive or predominant practice and proficiency expected of new veterinary school graduates. J Am Vet Med Assoc. 2004;224:1780-7.

16. Clarke PM, Al-Alawneh J, Pitt RE, Schull DN, Coleman GT. Client perspectives on desirable attributes and skills of veterinary technologists in Australia: considerations for curriculum design. J Vet Med Educ. 2015;42:217-31.

17. Doucet MY, Vrins A. The importance of knowledge, skills, and attitude attributes for veterinarians in clinical and non-clinical fields of practice: A survey of licensed veterinarians in Quebec, Canada. J Vet Med Educ. 2009;36:331-42.

18. Jackson L, Ervin H, Gardner P, Schmitt N. Gender and the internet: Women communicating and men searching. Sex Roles. 2001;44:363-79.

19. Smith G. Does gender influence online survey participation? A record linkage analysis of university faculty online survey response behavior. San José, CA: San José State University, Faculty Publications. ERIC Document Reproduction Service No ED 501717. 21 pp. 2008.

20. Haldane S, Hinchcliff K, Mansell P, Baik C. Expectations of graduate communication skills in professional veterinary practice. J Vet Med Educ. 2017;44:268-79.

21. Rhind SM, Baillie S, Kinnison T, Shaw DJ, Bell CE, Mellanby RJ, et al. The transition into veterinary practice: opinions of recent graduates and final year students. BMC Med Educ. 2011;11:64.

22. Foschi M, Freeman S. Inferior performance, standards and influence in same sex dyads. Can J Behav Sci. 1991;23:99-113.

23. Foschi M, Lai L, Sigerson K. Gender and double standards in the assessment of job applicants. Soc Psychol Quart. 1994;57:326-39.

24. Eckardt-Erlanger AC, Tsytsarev SV. The relationship between empathy and personality in undergraduate students' attitudes toward non-human animals. Soc Anim. 2012;200:186-90.

25. Williams B, Brown T, Mckenna L, Boyle MJ, Palermo C, Nestel D, et al. Empathy levels among health professional students: a cross sectional study at two universities in Australia. Adv Med Educ Pract. 2014;5:107-13. 